\title{
Urgences
}

\section{Le salut sans drapeau}

\section{Jean-Marc Cormier}

Numéro 1, 2e trimestre 1981

URI : https://id.erudit.org/iderudit/025017ar

DOI : https://doi.org/10.7202/025017ar

Aller au sommaire du numéro

Éditeur(s)

Urgences

ISSN

0226-9554 (imprimé)

1927-3924 (numérique)

Découvrir la revue

Citer ce document

Cormier, J.-M. (1981). Le salut sans drapeau. Urgences, (1), 102-110.

https://doi.org/10.7202/025017ar

Ce document est protégé par la loi sur le droit d'auteur. L'utilisation des services d'Érudit (y compris la reproduction) est assujettie à sa politique d'utilisation que vous pouvez consulter en ligne.

https://apropos.erudit.org/fr/usagers/politique-dutilisation/
Cet article est diffusé et préservé par Érudit.

Érudit est un consortium interuniversitaire sans but lucratif composé de l’Université de Montréal, l'Université Laval et l'Université du Québec à Montréal. Il a pour mission la promotion et la valorisation de la recherche. https://www.erudit.org/fr/ 
JEAN-MARC CORMIER

le salut sans drapeau 
salut cajuns et acajuns

salut frères noirs d'Haïti battus par Duvalier

salut gens du Cambodge

salut mort-nés du Bengladesh

juifs-français juifs-allemands juifs-russes

salut chair à canons

diplômés des crématoires

accidentés de la chasse

victimes de la bêtise humaine

salut nègres des amériques

dont les ancêtres ont été esclaves des grands de ce monde et dont les yeux des fils et des filles

sont des charbons ardents

témoins de tant d'infamie

salut arabes de Paris

fils d'Alger aux zobs électriques

qui crachent dans la gueule de fonctionnaires à l'immigration

des spots de lumière spermatozoïde

pédérastes

qui couleront dans leurs gorges chaudes jusque dans leurs

entrailles merdeuses

en échange d'un visa ou d'un permis de travail

salut ahmeds empalés armands déserteurs jos fusillés et fernandos torturés

de Corée d'Indochine de 39-45 du Vietnam

ou d'ailleurs dans le temps et l'espace

qui s'entremêlent quand il s'agit de tuer

salut cheap labor de Québec Toronto Halifax Vancouver

New-York Détroit Philadelphie Boston

ratés à-plat-ventrés sur les trottoirs étoilés d'Hollywood

de Londres

ou de Paris-Lumière 
salut plèbe de Pékin d'Honolulu de Singapour

de Rotterdam et de Sherbrooke

salut crottés de toutes sources

salut vauriens de tout acabit

saluu petits prostitués de Rome

jeannettes battues maries violées suzannes mortes en couche vieilles femmes fourbues

fillettes abandonnées outragées déflorées à coups de pic

enfants jetés en bas des ponts

à glace

déchiquetés des autoroutes

salut folles de la Taverne Altesse

anticorps-sociaux parasites-assis

arriérés-persistants

appelés-des-bas-fonds élus-de-la-gale assoiffés-de-néant

artefacts-arthritiques ataxiques ou atomisés

lesbiennes-gloutonnes actrices-salopes

bédouins-beatniks bélîtres-lourdauds

canaris-débauchés dévergondés-pervertis

délinquants-désespérés colporteurs-crétins

goitreux-impotents

traîtres faux-jetons

valets-vermisseaux

champis

chevaliers-du-courant-d'air

circoncis et damnés

idiots-intarissables

bureaucrates-ébourgeonnés

cadres écartelés caìds-cagneux camés-cannibales

braillards-puants

cancres-truands brutes-cancéreuses

exhibitionnistes du Parc Lafontaine

en habits du dimanche en pleine nuit du samedi

le petit coq en or à la Tintin

tourné pendant de longues minutes dans le toupet rebelle

domestiqué au Brylcream

et qui montrent leurs queues à des papas fictifs accotés sur les arbres

et qui se meurent de peur d'être tabassés par les flics

et qui meurent de plaisir devant une paire d'yeux

compatissants 
et qui crèvent de désespoir

et qui laissent tomber leur gourme

sur la neige déjà salie par leurs pas

avant d'aller rendormir leurs remords dans des lits vides

dans la plus ahurissante solitude

et froids

au bord de la folie démente

rêvant de mourir enfin endormis

salut chiens écrasés de la Une du Journal de Montréal

salut frères sales et démunis

salut poules aux oeufs d'or aux petites voix criardes

qui chantent du western dans les clubs de nuit

danseuses topless bottomless brainless

qui chantent et qui dansent si naivement

qu'on dirait qu'elles chantent et qu'elles dansent

pendant qu'elles pleurent des larmes de sang

et qu'elles se tuent graduellement

salut sauterelles salut salopes salut putains

salut criminels des bas quartiers

témoins hurlants dès l'enfance de toutes les bassesses

victimes de tous les dérangements

gogos harnachés par la publicité

éphèbes-castrés politiciens-véreux bagnards-guillotinés

führers-de-la-folie-furieuse

magistrats-crapuleux

exécutés de tous les régimes

bossus-éreintés mendiants

bornés de toutes les castes

soviets bouffis $d u$ saint-système

subalternes lymphatiques

m'as-tu-vu hystériques

quidams bien-pensants esclaves du bien pensé

gradés bilieux aux teintes jaune-vert

salut pieds-bots sur les trottoirs

inconnus de l'Abitibi qui avez sué pour la Domtar

salut crasseux des Hauts de la Beauce

qui avez peiné pour les Breaky

calés jusqu'au cul dans la neige trempe

pour le baloney quotidien les bines à m'lasse pis l'rôti d'porc 
salut fraudeur aveugle de Pic Dur salut jumelles engrossées à treize ans par la même queue aux premières amours courbaturées dans la crèche à Nelly enveloppées dans une odeur de sperme et de marde dans l'étable du rang 5 salut frères sales et démunis époumonnés et cul-terreux culs-de-jatte et manchots aveugles et veules démembrés de toutes les nations bohémiens-opiomanes bouche-trous abrutis blasphématoiresagenouillés

automates-agents-doubles moutons sacrifiés troupeaux agglutinés dans les cités autrefois menteurs histoire falsifiée aujourd'huis manipulés demains régis assujettis contrôlés ballots des bad-lands aux bamboulas sanglantes bánnis proscrits exilés baragouineux métaphysiques rois-fous empereurs-déments caligulas-colonels bardes de la terreur mutants de plâtre baronets de palmarès bâtards sans âme sans coeur et sans pays salut femmes qui bouffent du Zola dans la vraie vie les doigts brisés par le travail vagins séchés par les bonnes moeurs salut abrutis du travail à la chaîne rescapés des usines d'armes hallucinés de Gogh et de Bosch paumés des temps présents sortis des temps jadis hurlements de terreur poussés par toutes les gorges salut brasseurs de bines et tordeurs de Pepsi cadres de portes branlants catherines pleines jusqu'aux anses et de caca et de pipi salut estropiés de toutes les guerres infirmes syphilitiques stériles et impuissants de toutes

salut victimes de toutes les maladies les races lépreux gangréneux typhiques alcooliques aliénés anémiés angineux tuberculeux ankylosés cancéreux hémorroïdés j'en passe 
analphabètes apatrides amputés salut mes frères salut les miens salut tous les crasseux de toutes les classes sociales

j'entends

j'entends comme un grondement musical

i'entends comme un murmure comme une rumeur qui monte une rumeur infinie qui roule comme une vague

- comme une voix unique et nombreuse en même temps 300 milliards de voix par la terreur unies dans un même

* cri qui ne sait plus s'éteindre 300 milliards de voix qui chantent toutes ensemble j'entends des pas des pas qui marchent en cadence et font trembler la terre sur son axe des bruits de chaises roulantes de cannes et de béquilles des rires cristallins des cris de joie des pleurs j'entends comme un respir unique qui ronfle entre les hêtres 300 milliards de souffles ont envahi la terre et je suis envahi par toutes les tornades tous les typhons toutes les tempêtes et tous les ouragans et cette voix unique constituée de 300 milliards de voix réunies monte et monte en moi jusqu'à m'ouvrir la gueule comme un copieux repas poussé par une bouteille entière du plus mauvais cognac et qui se dégueulerait tout seul malgré moi dans la rue je suis ivre de toutes les ivresses révolté de toutes les révoltes hehreux de toutes les joies animé par tous les désirs poussé par toutes les passions paranoïaque de toutes les paranoïas schizophrène de toutes les schizophrénies fou de toutes les folies sage de toutes les sagesses rempli de l'univers entier qui se débecte en même temps qu'il se déguste 
l'alpha et l'omega

le début et la fin

le vide et le plein

et toute cette charge de souvenirs

qui roule et tangue et chavire

quelquefois entre l'oreille gauche et l'oreille droite

tous ces yeux qui ont vu tous ces paysages

qui sont sortis des cavernes et sont allés sur Vénus

ces nez innombrables qui ont sniffé ces innombrables culs

ces mains qui ont caressé toutes les chairs

ce coeur en chamade qui a bêtement battu toutes les mesures

et soutenu tous les rythmes

ces traces de pas que ces pieds ont tracées dans toutes les

ce ventre qui a assumé toutes les faims

neiges

tous les désirs

toutes les soifs

et toutes les peurs

cette bouche qui a goûté tous les sucres et tous les sels ces oreilles qui ont entendu toutes les plaintes tous les

toutes les musiques et tous les bruits de l'enfer

chuchotements 
et cette voix unique de la multitude monte en moi jusqu'à me faire éclater 1a cervelle et quand tout est sorti j'entends encore cette voix mais cette fois hors de moi et je ne suis plus qu'un dans la foule ajoutant ma petite voix à toutes les autres voix 
le cercle est fermé

tous les péchés sont absous

toutes les dettes karmiques ont été payées

et il ne reste plus que ce chant

qui monte incessamment

tous les bâtards du monde se sont enfin unis

et n'ayant jamais eu de pays

ils se donnent une planète

et c'est encore trop peu

pour leur immense appétit 